\title{
What EFL Learners Say in Managing Their Speech During Academic Presentations
}

\author{
Lucky Rahayu Nurjamin, Asep \\ Nurjamin Institut Pendidikan Indonesia \\ Garut, Indonesia \\ nurjaminlucky@yahoo.com
}

\author{
Rima Melati \\ Universitas Pendidikan Indonesia \\ Bandung, Indonesia
}

\begin{abstract}
Capturing the EFL students in managing their speaking phenomenon led the study to focus on scrutinizing the categories of fillers, as well as identifying the functions of each filler used in an academic presentation. This case study was conducted at one of educational universities in EFL settings with 81 English education students involved as participants. The data were collected through observation, the data were utterances produced, particularly fillers. The data were then analyzed inductively, particularly by using the framework of Chapetón Castro (2009) for the filler analysis. This resulted, first, three categories of filler -simple words, phrases, and clauses- with 27 different examples. There were 15 simple-word filler (ehm, and, oke, so, like, eh, yes/ ya, no, because, but, now, then, actually, right? and understand?), 5 phrase fillers (and then, oh ya, yes heem, so that, and of course), and 7 clause fillers (I think, can you get it?, do you understand?, I mean, you got it?, get it?, and you understand?). Second, 11 functions of fillers were found covering: opening frame marker, closing frame marker, turn takers/ turn givers, turn keepers, topic switchers, information indicators, repair markers, agreement marker, disagreement marker, response/reaction markers, and checking understanding markers.
\end{abstract}

Keywords: academic presentation, EFL students, fillers

\section{INTRODUCTION}

Academic presentation is typically a demonstration, lecture, or speech meant to inform or persuade. Girard, Pinar, and Trapp (2011) and Brooks and Wolson (2014) state that using oral presentation in their classroom leads to better class interaction and participation, increases the interest in learning and improves the students' communication and presentation skills. Nevertheless, during this process, students produced some speech sounds when they present the main messages or materials. These speech sounds are called fillers. Even though the students have prepared their academic presentations, they produce fillers subconsciously in the implementation.

Fillers are every word, phrase, and clause spoken to fill up gaps in utterances. According to Erten (2014), fillers are discourse markers that speakers use when they think or hesitate during their speech or elaborate on the next topic or sentence. Fillers can be classified into some forms based on their word construction. It can be simple words, phrases, and clauses (Stevani, Sudarsono, \& Supardi, 2018). A simple word filler is constructed with only one single word such as but, okay, well, um, yeah, uh, eh, and, see, so and right. Fillers also can be in form of phrase. A phrasal filler is a group of words without a subject or a verb such as by the way and how to say. The next is a clausal filler is a group of words that have both subjects and predicates such as I mean and you know. Fillers can also be classified based on their functions. There are at least five functions of fillers that will be explained further. They are hesitating, empathizing, mitigating, editing term, and timecreating devices (Kharismawan, 2017; Stenström, 1994). The researcher analyzed the productions of fillers and defined the functions by considering the context of the situation from the utterances.

However, the usage of fillers has effects on the value of the speaker in front of the listeners, either negative or positive impact. According to Duvall, Robbins, and Divett (2014) the negative impact of fillers occurs when a speaker overuses those words showing the hesitation of the speaker in delivering the message. As a result, the audience becomes difficult to understand the main message of the topic. On the other hand, fillers help a speaker to recall the words that they need to deliver next. It gives time for the speaker to elaborate on the next sentences. Moreover, fillers are naturally used during the speech.

Numerous relevant studies have been conducted in analyzing filler. Stevani et al. (2018) conducted a study about the types and the functions of fillers. The study analyzed filler usage by using corpus. As a result, 12 fillers are found in this study. They are ehm, okay, actually, so, and, and then, I mean, something like, well, then, right, how to say.

Moreover, fillers have several functions such as to allow the speaker to think, to restate or repair what the speaker has said, to initiate the speech, and to emphasize the main point of the topic. The most frequent function showed in their study is as turn keepers to hold the conversation or to give the speaker time to think about the next topic. Furthermore, Brinton (1996), Chapetón Castro (2009) and Erten (2014) carried out the study about fillers. This study describes the functions of discourse markers in a textual context. Although there is no specific description of the functions of fillers, this study agrees that the functions of discourse markers can be used to describe the functions of fillers as well because filler is a part of discourse markers. In regards, they tended to analyze the types of fillers and the functions of fillers. This means they did not analyze the dominant fillers that are produced by students and classify the types of fillers based on their function. Therefore, in filling the gap, this study concerned on the types of fillers based on their functions and the dominant filler produced by college students. 


\section{METHOD}

Qualitative research embracing the case study design was chosen in this study. This study was taken place at one of the educational universities in the EFL setting. The participants are 81 students from The Third Grade of English Department Students in Academic Year 2019/2020. The data in this study were fillers that are uttered by college students during performing academic presentations (Taylor, 2008). Therefore, the data source were utterances that were produced by college students during delivering the materials only (Schreiber \& Asner-self, 2011). In collecting the data, the observation was conducted in 4 times since there were 4 classes in The Third Grade of English Department Students in Academic Year $2019 / 2020$ on the 24th of Mei, 2019. The data collection was audio and video recordings as a result of observation in the classroom. The tools were used in this study are Electronic Audio Recorder of Vivo Y69 smartphones, video recorders, and notebooks. There were several processes of observation. Moreover, the data of observation were sorted out manually from the corpus linguistics by separating the fillers from other words. The data were then analyzed inductively, particularly by using the framework of Chapetón Castro (2009) for the filler analysis.

\section{FINDINGS AND DISCUSSION}

\section{Findings}

\section{a. Types of fillers}

The result showed that there were 27 types of fillers produced by the students while delivering their academic presentations. They are ehm, and, oke, so, like, and then, eh, yes/ya, no, because, but, I think, now, then, actually, can you get it?, do you understand?, oh ya, yes heem, so that, I mean, you got it?, right?, understand?, of course, get it?, and you understand?. Filler 'ehm' becomes the most frequently produced by the students with 625 appearances. Table 1 below shows those 27 fillers with their frequency.

Fillers that produced by the students in delivering an academic presentation can be classified based on their construction into simple words, phrases, and clauses. First, there were 15 fillers in the form of simple words. The fillers were classified as simple words because they were constructed with only one single word. They were ehm, and, oke, so, like, eh, yes/ ya, no, because, but, now, then, actually, right? And understand? Among those fillers, ehm is frequently used by the students $(50.60 \%)$. The example of those fillers can be shown in these utterances as follows:

S3a $\quad:$... The quantity maxim is that ehm make your contribution as informative $\underline{\mathbf{e h m}}$ as $\underline{\mathbf{e h m}}$ attitude

S1d : ... I'm S1d as a moderator and the second presenter. And the first presenter is S2d. And the third presenter is S3d. And the forth presenter is ehm S4d. $\underline{\text { And }}$ the fifth presenter is S5d. And he last presenter is S6d.
S2g : Oke I will explain about two kinds of face. The first is positive face and the second negative face. S2i $\quad$ : ... for instance desire people appreciation of his or her fighting. So it means that ehm individual someone wants to be appreciated by others and keeping self-image in social group.

S4a $\quad: \ldots$ She is a lie but but if she answers like why don't we it out it out for a chance.

Second, there were 5 fillers in the form of phrases. There were and then, oh ya, yes heem, so that, and of course. They were classified as phrases because they were constructed by a group of words without a subject or a verb. In this form, filler and then most frequently occurred by the students. The fillers as shown in (16) until (20).

(5) S7h : the last result is off record strategies, the researcher found one hundred ehm one hundred ehm five utterances off-record strategies. And then she counted that 2 utterances using association clues. And then 16 utterances using presuppose. And then 6 utterances using overstate. And then 46 utterances using tautologies. And then 2 utterances using metaphors. And then 3 utterances using contradiction. And then 2 utterances using rhetorical questions.

S1a : And the second presenter ehm is S2a. And ehm the next is S3a and the last is S4a. Oh ya <laugh> S4a. I'm sorry $<$ laugh $>$

S1a : Yes heem harusnya kan kalo kita nanya kamu punya waktu ngga? Ehm ini jawabnya malah iya ini cenah jam nya setengah sepuluh ...

The last is in the form of clauses. The clausal fillers are a group of words that have both subjects and predicates. There were 7 fillers. They were I think, can you get it?, do you understand?, I mean, you got it?, get it?, and you understand?. In this form, filler I think was frequently used. Each of them is exemplified in the utterances as follows:

(8) S1e : Oke I think enough from our group. Thank you so much for your attention.

(9) S3c : There is to exesive ehm and in here ehm just just in the answer is ehm the answer that information is required jadi like as request. Can you get it?

(10) S3f : For the second, Mrs. Yus just tell us that she suddenly today she have another schedule with her lecturer. It means that Mrs, Yus will not enter to our class. So we will not have o'clock class with her today. Do you understand?

\section{b. Functions of fillers}

Beside base on the word constructions, fillers can be classified based on their functions. According to Chapetón Castro's theory, there were 14 functions of fillers. In this study, there were 11 functions of fillers that found in delivering students' academic presentations. 


\section{Opening Frame Markers}

There were 4 fillers as opening frame markers. They were oke, ehm, now, and ya. These fillers were used when the speakers initiate discourse, including asking the attention of the hearers. The example of these fillers in the utterance shown below:

(11) S2i : $\underline{\text { Oke next positive face. Positive face is }}$ defined as individual desire or person that his or her personality is appreciated by others.

S1a $\quad \underline{\text { Ehm }}$ we are from first group. And today we would like to present the material about the principle.

S5d : Oke Now I will explain about type of presupposition. The first is the existential presupposition.

\section{Closing Frame Markers}

In function as closing frame markers, there are 2 fillers. They are oke and I think. These fillers can be used to end the discourse. The following utterances taken from the data illustrate fillers as closing frame markers:

(14) S4d $\quad: \ldots$ It is able to give ehm conclusion or initial ehm initial of the speaker before giving a speech ehm in ehm that what will be convey. It also understood by ehm the other speech partner. Oke.

(15) S6e : research on Lyons nineteen seven $1995 \mathrm{ehm}$ entailment plays an important role in all theories of meaning between sentences. I think enough for me.

\section{Turn Takers/ Turn Givers}

There were 2 fillers as turn takers or turn givers. They were and and oke. Fillers of turn takers can be used to aid the speaker in acquiring or relinquishing the floor. In other words, it is to give a chance or give the turn to other speaker speak. These fillers were used by the students as illustrated by the following example:

(16) S1i : And the last explanation will be explained by $\mathrm{S} 7 \mathrm{i}$

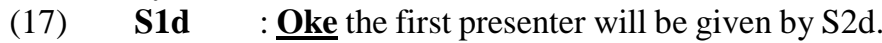
S2d start.

\section{Turn Keepers}

Turn keepers were used to keep the turn in conversation. In other words, these fillers can be used to hold the floor or to give time to the speaker to think about the next word. There are 4 fillers as turn keepers. They were ehm, and, oke and like. The most frequently occurred was ehm with 610 appearances. These example illustrated the function of turn keepers:

(18) S1g : And this discuss the FTA ehm this discuss about politeness politeness since from whom the speakers. It will form $\underline{\text { ehm }}$ the special expression ...

S1j : First one is appraisal appraisal is someone who something appraise is something that appraised by someone. And the other one is affect. Affect is the appraisal it can be negative or positive. If that related to the feeling.
S1j : And other questions? Oke just one question. Wait a moment. Oke I'd like to answer ehm just question graduation actually some sources that graduation is ...

\section{Topic Switcher}

There were 3 fillers that can be functioned as topic switcher. They were so, and, and now. These fillers used by the speaker to initiate new stage or topic in the classroom discourse and to get the attention of the hearers as shown in the following examples:

(21) S5b : Oke so here cooperative principle. Grice purposes that ordinary conversation ehm the speaker and the listener share the cooperative principle.

S4c : And more example quality maxim ehm the girl 'do you know where the Big Ben Clock Tower is? And anwer the boy 'It's in London'.

S1f : Oke now ehm the last ehm ehm example from implicature ehm here there is a man and woman.

\section{Information Indicators}

In the functions of information indicators, there were 6 fillers found from the data. They were so, and then, because, then, actually and so that. They can be functioned to denote either new or old information. The most frequently occurred in this function was so with 49 appearances. The examples of information indicators is shown as follows:

(24) S5b : $\underline{\text { So }}$ in in ordinary conversation, the listener and the speaker ehm always always share the cooperative principle.

(25) S7h : And then she counted that 2 utterances using association clues. And then 16 utterances using presuppose.

(26) S7g : ... someone can can do ehm can express their common expression because our ehm FTA And then for say no when say no is negative ehm FTA because ehm say no is same with negative request ...

\section{Repair Marker}

Repair markers were used when the speaker repair the wrong word in the first place. In this study, there were 3 fillers as repair markers. They were eh, but and I mean.

(27) S1a : today we would like to present the material about the principle $\underline{\text { eh }}$ the cooperative principle

(28) S6e : Oke I'm gonna answer no <laugh> we are not showing the example but we are showing the data of this jurnal so of you guys can know.

\section{Agreement Markers}

Agreement markers are included interpersonal functions to express understanding and agreement. Based on the findings from the data, there were 24fillers as agreement markers. They were yes/ya, yes heem, oh ya, and of course. The following utterances illustrated those fillers:

(29) S2c : Why we call why we call this is the <cough> the base eh not the base or conversation principle 
because the motorist say that. Ehm the purpose of of question from the from the questioner. Yes thank you. S1a $\quad:$..... do you have the time? Jawabnya apa kira kira?

A : Yes, I have.

S1a : Yes heem

(31) S1a : my name is S1a as moderator and the second presenter and the first presenter by eh ... ((laugh)) $\underline{\mathbf{o h}}$ ya sorry $(($ laugh $))$ eh ehm moderator and first presenter

\section{Disagreement Marker}

In this study, the one and only filler that showed this function was 'no' where it was occurred 4 times. This filler used to fulfill interpersonal function to state disagree about statement. The following is the example of disagreement marker

S6e : I'm gonna answer no <laugh> we are not showing the example but we are showing the data of this jurnal.

\section{Response/ Reaction Markers}

Based on the analysis of data, there were 2 fillers that found as response or reaction markers. They were yes/ ya and no. they are functioned to give feedback/ response from questions. The example of those fillers can be shown in these utterances as follows:

(33) S3f : For the second, Mrs. Yus just tell us that she suddenly today she have another schedule with her lecturer. It means that Mrs, Yus will not enter to our class. So we will not have o'clock class with her today. Do you understand?

A : $\underline{\text { Yes. }}$.

(34) S6f : It's impossible it's Aji ehm has not has not finished his task has not has not finished a task if if he have edited his task. You got it?

A : $\underline{\text { No }}<$ laugh>

\section{Checking Understanding Markers}

There were 7 fillers that occurred as checking understanding markers. They were do you understand?, can you get it?, get it?, you get/ got it?, right?, understand?, and you understand?. These fillers fulfilled interpersonal functions to check understanding about what the speaker said to the hearers. They are exemplified respectively as follows:

S3f : For the second, Mrs. Yus just tell us that she suddenly today she have another schedule with her lecturer. It means that Mrs, Yus will not enter to our class. So we will not have o'clock class with her today.

\section{Do you understand?}

S3c : There is to exesive ehm and in here ehm just just in the answer is ehm the answer that information is required jadi like as request. Can you get it?

\section{Discussion}

27 fillers were found produced by the students during academic presentation. Those were classified into three forms of filler; simple words, phrases, and clauses. There were 15 fillers in the form of simple words. The fillers were classified as simple words since they were constructed with only single word. Second, there were 5 fillers in form of phrases. The last is in the form of clauses. There were 7 fillers that are a group of words that have both subjects and predicates.

As in line with Stevani et al. (2018) who utilised the Chapetón Castro's theory, there are 14 functions of fillers. They are opening frame marker, closing frame marker, turn takers/turn givers, turn keepers, topic switchers, information indicators, sequence/ relevance markers, repair markers, agreement marker, disagreement marker, response/reaction markers, checking understanding markers and confirmation markers. However, the result of Stevani's work was different especially in the functions of fillers. The study found 4 functions. They were opening frame markers, information indicators, turn keepers, and repair markers. Whereas, this study found 11 functions of fillers. There were opening frame marker, closing frame marker, turn takers/turn givers, turn keepers, topic switchers, information indicators, repair markers, agreement marker, disagreement marker, response/reaction markers, and checking understanding markers. In this study, the dominant fillers produced by the student based on the function is filler ehm as turn keeper. It has occurred 610 times (49.39\%). This filler was used to hold the floor or to give time to the speaker to think about the next word including asking the attention of the hearers.

The word and and think cannot be classified as filler. Both words and and think have similar functions as Stefani's work which classified words and as a conjunction to compound two objects while word think as a verb in the sentence. In addition, both words can be classified as filler when the speaker used and followed by long pause.

In this context, non-native speakers use fillers more than native ones (Müller (2004) as cited in Erten (2014). However, the usage of fillers has effects on the value of the speaker in front of the listeners, either negative or positive impact. According to Duvall et al. (2014) and Pamolango (2016) the negative impact of fillers occurs when a speaker overuses those words showing the hesitation of the speaker in delivering the message. As a result, the audience becomes difficult to understand the main message of the topic. On the other hand, fillers help a speaker to recall the words that they need to deliver next. It gives time for the speaker to think the next sentences. Moreover, fillers are naturally used during the speech.

\section{CONCLUSION}

This can be concluded that there are 3 types of fillers produced by students based on the constructions such as simple words, phrases, and clauses. There were 15 fillers in the form of simple words. The fillers were classified as simple words since they were constructed with only one single word. Second, there were 5 fillers in form of phrases. The last is in the form of clauses. There were 7 fillers that are a group of words that have both subjects and predicates. 
Second, based on the previous chapter, there were 11 functions that can be used by students in delivering academic presentation. They were opening frame marker, closing frame marker, turn takers / turn givers, turn keepers, topic switchers, information indicators, repair markers, agreement marker, disagreement marker, response/reaction markers, and checking understanding markers.

\section{REFERENCES}

Brinton, L. (1996). Pragmatic markers in English. Grammaticalization and discourse functions. Berlin/New York: Mouton de Gruyter.

Brooks, G., \& Wolson, J. (2014). Using oral presentations to improve students English language skills. Kwansei Gakuin University Humanities Review, $19,199-212$.

Chapetón Castro, C. M. (2009). The use and functions of discourse markers in EFL classroom interaction Profile Issues in Teachers Professional Development, (11), 57-78.

Duvall, E., Robbins, A.S., \& Divett, S. (2014). Exploring filler words and their impact. p. $35-50$

Erten, S. (2014). Teaching Fillers and Students' Filler Usage: A Study Conducted at ESOGU Preparation School. International Journal of Teaching and Education, 2(3). 67-79.
Girard, T., Pinar, A. M., \& Trapp, P. (2011). An exploratory study of class presentations and peer evaluations: Do students perceive the benefits? Academy of Educational Leadership Journal, 15(1). 77-93.

Kharismawan, P. Y. (2017). The Types and The Function of Fillers Used in Barack Obama's Speech. International Journal of Humanity Studies, 1(1), 111-119. doi: 10.24071/ijhs.2017.010112

Müller, S. (2004). 'Well you know that type of person': Functions of well in the speech of American and German students. Journal of Pragmatics, 36(6), 1157-1182. doi: 10.1016/j.pragma.2004.01.008

Pamolango, V.A. (2016). An Analysis of the Fillers Used by Asian Students in Busan, South Korea: A Comparative Study. International Journal of Languages, Literature and Linguistics, 2(3). 96-99.

Schreiber, J. B., \& Asner-Self, K. (2011). Educational research: interrelationship of questions, sampling, design, and analysis. John Waley and Sons. Inc: United States of America.

Stenström, A. (1994). An Introduction to Spoken Interaction. London: Longman.

Stevani, A., Sudarsono, S., \& Supardi I. (2018). An Analysis of Fillers Usage in Academic Presentation. English Language Education Study Program. Jurnal Pendidikan dan Pembelajaran Khatulistiwa. 7(10). 1-9.

Taylor, C. (2008) What is corpus linguistics? What the data says. ICAME Journal, 32. 179-200. Retrieved from http://sro.sussex.ac.uk/53389. 